\title{
Mechanical Properties of Foundation Concrete Exposed to a Swampy Area for a Prolonged Period
}

\author{
Nsahlai Leonard Nyuykongi ${ }^{1,2,3}$, Yamb Bell Emmanuel ${ }^{4}$, Ndigui Bilong ${ }^{4,5}$, Blaise Ngwem Bayiha ${ }^{4}$, \\ Mbuh Moses Kuma ${ }^{3}$ \\ ${ }^{1}$ Department of Geomechanics of Soils, Laboratory of Mechanics, Post Graduate School for Pure and Applied Sciences, University of Douala, \\ Douala, Cameroon \\ ${ }^{2}$ Department of Civil Engineering and Architecture, National Higher Polytechnic Institute (NAHPI), University of Bamenda, Bambili, \\ Cameroon \\ ${ }^{3}$ Department of Civil Engineering, Ecole Normale Supérieure Enseignement Technique (ENSET), University of Bamenda, Bambili, \\ Cameroon \\ ${ }^{4}$ Department of Civil Engineering, Ecole Normale Supérieure Enseignement Technique (ENSET), University of Douala, Douala, Cameroon \\ ${ }^{5}$ Laboratory of Materials Analysis, Local Materials Promotion Authority, Yaounde, Cameroon
}

\section{Email address:}

nsahlaileonardn@gmail.com (N. L. Nyuykongi)

\section{To cite this article:}

Nsahlai Leonard Nyuykongi, Yamb Bell Emmanuel, Ndigui Bilong, Blaise Ngwem Bayiha, Mbuh Moses Kuma. Mechanical Properties of Foundation Concrete Exposed to a Swampy Area for a Prolonged Period. Journal of Civil, Construction and Environmental Engineering. Vol. 6, No. 5, 2021, pp. 126-134. doi: 10.11648/j.jccee.20210605.11

Received: November 30, 2020; Accepted: June 15, 2021; Published: October 15, 2021

\begin{abstract}
A total of 24 concrete samples of nominal dimensions $300 \mathrm{~mm} \times 150 \mathrm{~mm} \times 100 \mathrm{~mm}$ each were produced for laboratory testing using six cement dosages of $150 \mathrm{Kg} / \mathrm{m}^{3}, 200 \mathrm{Kg} / \mathrm{m}^{3}, 250 \mathrm{Kg} / \mathrm{m}^{3}, 300 \mathrm{Kg} / \mathrm{m}^{3}, 350$, and $400 \mathrm{Kg} / \mathrm{m}^{3}$. Samples were buried at a swampy area with a moisture content of $67.38 \%$ for 56days, 84days, 112 days and 196days. For concrete dosed at $400 \mathrm{Kg} / \mathrm{m}^{3}$, compressive strengths of $20.8 \mathrm{MPa}, 19 \mathrm{MPa}, 16.5 \mathrm{MPa}$, and $12.7 \mathrm{MPa}$ were recorded for 56 days, 84 days, 112 days, and 196days, respectively. The modulus of elasticity for the concrete dosed at $400 \mathrm{Kg} / \mathrm{m}^{3}$ is $29741.38 \mathrm{MPa}$, and the Poisson ratio is 0.177 . The bulk modulus for concrete dosed at $400 \mathrm{Kg} / \mathrm{m}^{3}$ was found to be $15346.43 \mathrm{MPa}$ and the shear modulus was 12634.4 MPa. Concrete dosed at $150 \mathrm{Kg} / \mathrm{m}^{3}$ recorded a Von Mises stress of $15.407 \mathrm{MPa}$, while concrete dosed at $400 \mathrm{Kg} / \mathrm{m}^{3}$ recorded a higher von Mises stress of $21.984 \mathrm{MPa}$. The Von Mises stresses were far greater than most of the average uni-axial failure stresses. The maximum distortion energy for concrete dosed at $150 \mathrm{Kg} / \mathrm{m}^{3}$ is $9.028 \mathrm{KJ} / \mathrm{m}^{3}$, while that dosed at 400 $\mathrm{Kg} / \mathrm{m}^{3}$ has a distortion energy of $6.067 \mathrm{KJ} / \mathrm{m}^{3}$. Other mechanical properties such as the strains, principal stresses, and failure angles were also assessed. The general trend of the analyses revealed that prolonged exposure of concrete to a humid environment has an adverse effect on the engineering performance of concrete.
\end{abstract}

Keywords: Modulus of Elasticity, Von Mises Stress, Shear Modulus, Bulk Modulus, Distortion Energy, Principal Streses, Humid, Strains, Failure Angle

\section{Introduction}

Rising dampness occurs as a result of capillary suction of moisture from the ground into porous masonry building materials such as stone, brick, blocks, earth and mortar [10, 11]. It is a problem that is very common in older buildings, particularly those constructed without damp proof courses. However, it is gradually becoming a common issue with modern types of buildings as well. Over the years, many researchers have tried to define rising dampness from their own perspectives and new definitions keep on resurfacing as the years go by. When ground water reaches the foot of a wall, it tends to rise in the walling materials and continues to do so due to capillary action to various degrees of intensity [4, 5]. In the soil, between the surface of the earth and the groundwater, water may appear as gravitational water, i.e. water sinking into the groundwater, as capillary moisture, and as water vapour inside the pores of the soil. Capillary 
moisture is a possible moisture stress to structures. The amount of water rising capillarily from the soil depends on the type of soil, its capillarity, the groundwater level and the functionality of the underdrain network $[8,9]$. Especially the groundwater level may vary significantly with the time of year and with meteorological and climatological variations. The moisture content of soil is typically so large, that the relative humidity of the air inside the pores of soil is considered to be $100 \%$ (Dick, 1997). Having an insight of how prolonged exposure of a concrete element to humidity can affect the mechanical characteristics is very important to structural designers. For instance, if the designer knows to what extent prolonged humid exposure reduces the engineering properties of materials then the properties would be ameliorated prior to exposure of the element.

\section{Materials and Methods}

\subsection{Materials}

Water, sand, cement, and basalt gravel are the materials that were used for the production of specimens. The water that was used came from a borehole and was of drinkable quality and therefore suitable for concrete production. Medcem cement sold in bags of $50 \mathrm{~kg}$ was used for the study. Gravel that was used was bought from Kendeley quarry (see figure 1) in Bamenda and then transported to the point of usage at Bambuiy Geotechnical Laboratory in Bamenda. The sand had some debris, and so it was sieved manually through a $5 \mathrm{~mm}$ sieve before further usage. The gravel used was clean as it had been exposed to rain in the open air for long.

\subsection{Methods}

A total of 24 concrete specimens measuring $300 \mathrm{~mm} x$ $150 \mathrm{~mm} \times 100 \mathrm{~mm}$ each were produced for the compressive strength test and the determination of some other engineering properties (see figure 2). The preparation of these specimens commenced with the fabrication of wooden moulds which can be used to mould 8 concrete cubes per day. Moulding was carried out within a period of 3 days. Concrete specimens for concrete were fabricated with a constant water/cement ratio of 0.55 . Six cement dosages of $150 \mathrm{Kg} / \mathrm{m}^{3}, 200 \mathrm{Kg} / \mathrm{m}^{3}$, $250 \mathrm{Kg} / \mathrm{m}^{3}, 300 \mathrm{Kg} / \mathrm{m}^{3}, 350 \mathrm{Kg} / \mathrm{m}^{3}$, and $400 \mathrm{Kg} / \mathrm{m}^{3}$ were used in the study. The slump values from Abram's cone for concrete samples dosed at $150 \mathrm{Kg} / \mathrm{m}^{3}, 200 \mathrm{Kg} / \mathrm{m}^{3}, 250 \mathrm{Kg} /$ $\mathrm{m}^{3}, 300 \mathrm{Kg} / \mathrm{m}^{3}, 350 \mathrm{Kg} / \mathrm{m}^{3}$, and $400 \mathrm{Kg} / \mathrm{m}^{3}$ were $7.7 \mathrm{~cm}$, $7.2 \mathrm{~cm} 6.6 \mathrm{~cm}, 6.3,5.8 \mathrm{~cm}$, and $5.5 \mathrm{~cm}$, respectively. As stated before, a total of 8 samples were moulded within a time frame of 3 days. After each day's moulding, the test specimens were de-moulded after 24 hours and cured in a water tank by immersion for 28days. The 24 samples were then buried beneath the earth in Bamenda at a swampy area with average humidity of $62.83 \%$ moisture content.

The data was collected from the Bambuiy Civil engineering laboratory in Bamenda through experimentation and observation. Data concerning the sand equivalent test, slump test, grain size analysis test, and compressive strength were all obtained from the laboratory with the aid of various geotechnical and structural engineering equipment such as the grain size sieves, graduated cylinders, slump cone, and compression machine. As the tests were being performed, recording was done in a special recording booklet.

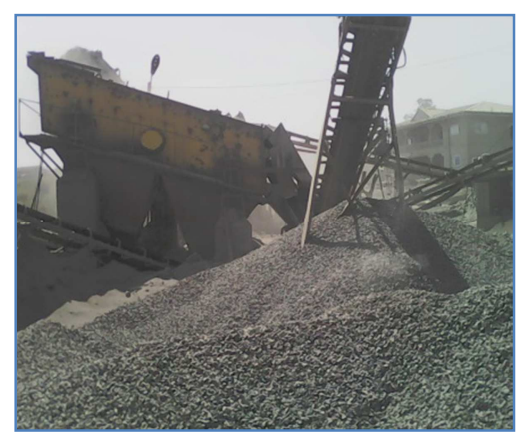

Figure 1. Photo showing Kendeley quarry in Bamenda where gravel samples were obtained (Source: Field research, 2020).

The Quartering Method was used for extraction of the aggregate samples. The quartering method consists of first taking a reasonable amount of a sample from the population. The sample is then divided into four nearly equal parts. Opposite quarters are then mingled to form two parts. The two parts are mixed and quartered again. This operation may continue several times until the aggregate particles are properly mixed. It should be recalled that the quartering operation is performed in order for the aggregates to be properly mixed so as to obtain representative samples.

The compressive and flexural strength results shall be analysed using BS 8110 (1997). This process shall be carried out considering dosages of $150 \mathrm{Kg} / \mathrm{m}^{3}$, $200 \mathrm{Kg} / \mathrm{m}^{3}$ and $250 \mathrm{Kg} / \mathrm{m}^{3}, \quad 300 \mathrm{Kg} / \mathrm{m}^{3}$, $350 \mathrm{Kg} / \mathrm{m}^{3}$ and $400 \mathrm{Kg} / \mathrm{m}^{3}$. After removing test specimens from the curing tank on each day, they were allowed to dry off for 30 minutes in the laboratory environment before being buried. Crushing then followed for 56days, 84days, 112days, and 196days, respectively for each cement type. Force values at failure were observed and recorded and the compressive stress values calculated using the following formula.

Compressive strength $=\frac{\text { Force at failure }}{\text { Cross }- \text { sectional area of specimen }}$

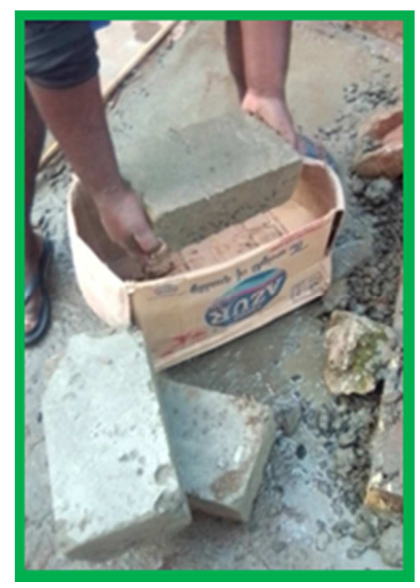

Figure 2. Packaging of samples in cartons and transportation to the lab. 


\section{Results and Discussions}

\subsection{Sand Equivalent Test}

The aim of the test is to determine the degree of cleanliness of sand. It was performed in accordance with BS 933-Part $8[6,7]$. The sand equivalence was $71.26 \%$. Thus, it can be deduced that the sand was clean and could be used with Ordinary Portland Cement. That explains why Ordinary Portland Cement was used in this research work.

\subsection{Grain size Analyses of Aggregates}

The granulometric analysis has as aim to determine the relative sizes of aggregates to be used for a particular job [13, 15]. Thus, it characterises the material by determining the sizes of the grains and proportion in percentage of grains for each particle size.

The grain size analyses were performed in accordance with BS 933-Part 1. The aggregate samples were placed successively in different columns of sieves and agitated for 5minutes. Thereafter, the samples were weighed. Percentage passing and retained were then computed and the results recorded as on tables. The results of the dry sieve analysis revealed that the sand had a coefficient of uniformity of 7.49. Moreover, the basalt gravel that was used had coefficient of uniformity of 4.28. Thus sand and gravel were well- graded according to (Vandevelde, 2008) and the Unified Soil Classification System [1, 2]. These showed that the aggregates were suitable for making concrete, unlike a gap-graded or poorly graded aggregate having coefficient of uniformity less than 1.00 .

\subsection{Slump Test}

The aim of the slump test is to determine the workability of concrete. It was performed in accordance with BS 933-Part 8.

Table 1. Slump test results.

\begin{tabular}{lll}
\hline Dosage & Slump (cm) & Water-cement ratio \\
\hline $150 \mathrm{Kg} / m^{3}$ & 7.7 & 0.55 \\
$200 \mathrm{Kg} / m^{3}$ & 7.2 & 0.55 \\
$250 \mathrm{Kg} / m^{3}$ & 6.6 & 0.55 \\
$300 \mathrm{Kg} / m^{3}$ & 6.3 & 0.55 \\
$350 \mathrm{Kg} / m^{3}$ & 5.8 & 0.55 \\
$400 \mathrm{Kg} / m^{3}$ & 5.5 & 0.55 \\
\hline
\end{tabular}

The results of the slump test indicating the workability of concrete are indicated on table 1 . For concrete dosed at $150 \mathrm{Kg} / \mathrm{m}^{3}, 200 \mathrm{Kg} / \mathrm{m}^{3}$ and $250 \mathrm{Kg} / \mathrm{m}^{3}, 300 \mathrm{Kg} / \mathrm{m}^{3}$, $350 \mathrm{Kg} / \mathrm{m}^{3}$ and $400 \mathrm{Kg} / \mathrm{m}^{3}$ the slump values were $7.7,7.2,6.6$, $6.3 \mathrm{~cm}, 5.8 \mathrm{~cm}$, and $5.5 \mathrm{~cm}$, respectively. It can be noticed that the greater the cement dosage the lesser the slump values at constant water cement ratio. This phenomenon can be attributed to the fact that any increment in a cement dosage would mean a corresponding cohesive bond of the cement matrix which resists concrete displacement on removal of the Abram's cone.

\subsection{Compressive Stress, Strain, and Young Modulus of Concrete}

The aim of the compression and strain tests is to determine the various compressive strengths and strain variations of concrete specimens $[14,16]$. The values would then be plotted. Valuable elastic constants such as Young's modulus of elasticity, and Poisson ratio are then evaluated. The test was performed in accordance with BS 1881-Part 166 (1983). Stress and strain values at failure are displayed on tables 2, 3 4 , and 5 and also on figure 3 with respect to various days and cement dosages.

Table 2. Computed compressive strength/strain values of concrete at $22^{\circ} \mathrm{C}$ ambient temperature.

\begin{tabular}{|c|c|c|c|c|c|c|}
\hline \multirow{2}{*}{ Curing age (Days) } & \multicolumn{2}{|c|}{$150 \mathrm{Kg} / \mathrm{m}^{3}$} & \multicolumn{2}{|l|}{$200 \mathrm{Kg} / \mathrm{m}^{3}$} & \multicolumn{2}{|l|}{$250 \mathrm{Kg} / \mathrm{m}^{3}$} \\
\hline & $\sigma(\mathrm{MPa})$ & $\varepsilon_{y}$ & $\sigma(\mathbf{M P a})$ & $\varepsilon_{y}$ & $\sigma(\mathbf{M P a})$ & $\varepsilon_{y}$ \\
\hline 56days & 10.5 & 0.00076 & 15 & 0.00074 & 17.2 & 0.00072 \\
\hline 84days & 9.6 & 0.00079 & 14.5 & 0.00076 & 15.8 & 0.00073 \\
\hline 112days & 8.4 & 0.00088 & 12.8 & 0.00083 & 14.1 & 0.00081 \\
\hline 196days & 7.8 & 0.00091 & 9.2 & 0.00087 & 10.5 & 0.00085 \\
\hline AVERAGE & 9.075 & 0.000835 & 12.875 & 0.0007825 & 14.4 & 0.0007775 \\
\hline Average Young modulus of elasticity $=\frac{\sigma}{\varepsilon}$ & \multicolumn{2}{|l|}{10868.26} & \multicolumn{2}{|l|}{16453.67} & \multicolumn{2}{|l|}{18520.90} \\
\hline
\end{tabular}

Table 3. Computed compressive strength/strain values of concrete at $22^{\circ} \mathrm{C}$.

\begin{tabular}{|c|c|c|c|c|c|c|}
\hline \multirow{2}{*}{ Curing age (Days) } & \multicolumn{2}{|l|}{$300 \mathrm{Kg} / \mathrm{m}^{3}$} & \multicolumn{2}{|l|}{$350 \mathrm{Kg} / \mathrm{m}^{3}$} & \multicolumn{2}{|l|}{$400 \mathrm{Kg} / \mathrm{m}^{3}$} \\
\hline & $\sigma(\mathrm{MPa})$ & $\varepsilon_{y}$ & $\sigma(\mathrm{MPa})$ & $\varepsilon_{y}$ & $\sigma(\mathrm{MPa})$ & $\varepsilon_{y}$ \\
\hline 56days & 17.6 & 0.000696 & 20.1 & 0.000652 & 20.8 & 0.000513 \\
\hline 84days & 16.2 & 0.000717 & 18.5 & 0.00066 & 19 & 0.000582 \\
\hline 112days & 14.2 & 0.000787 & 16.2 & 0.00068 & 16.5 & 0.000589 \\
\hline 196days & 10.9 & 0.000834 & 12.5 & 0.000699 & 12.7 & 0.000636 \\
\hline AVERAGE & 14.73 & 0.0007585 & 16.83 & 0.000673 & 17.25 & 0.00058 \\
\hline
\end{tabular}

Figure 3 shows the relationship between the average compressive strength and average Young modulus of the concrete. 


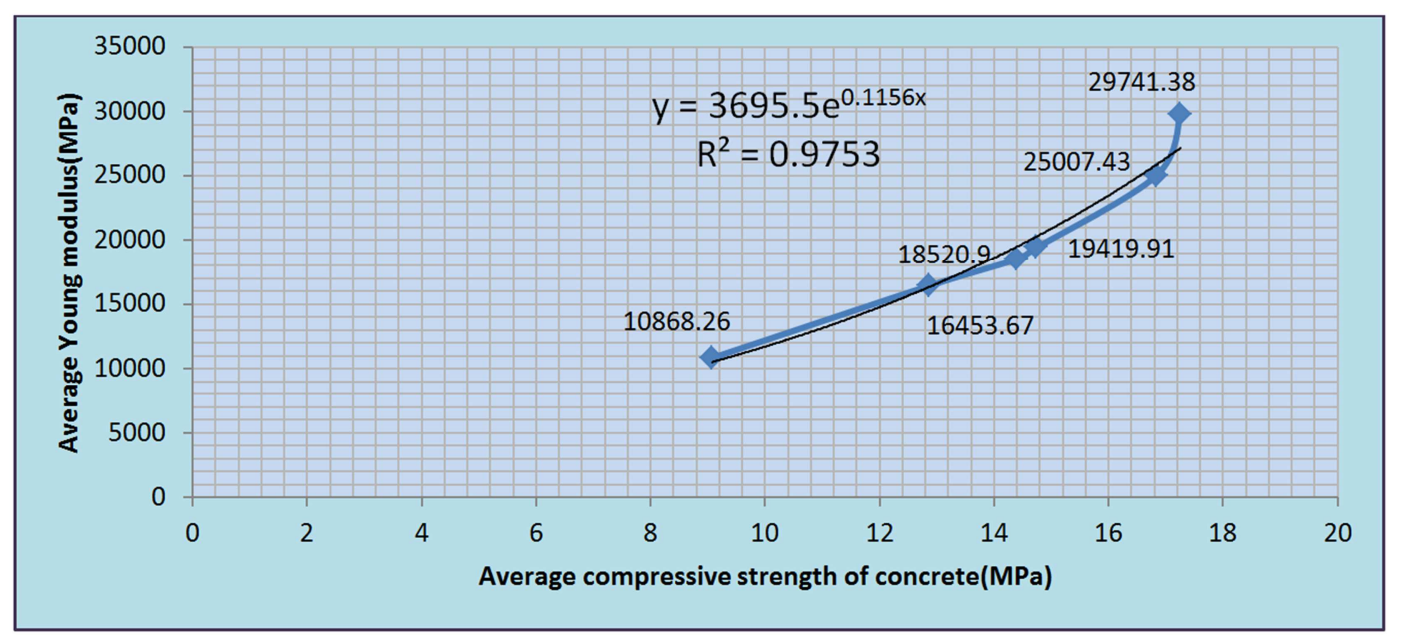

Figure 3. Relationship between the average Young modulus and average Compressive strength of concrete.

From table 2, table 3 and figure 3, the average compressive strength of concrete increases with increase in average Young modulus as the cement dosage goes up. Thus, the greater the cement content, the greater the compressive strength of the samples. However, the compressive strengths witnessed a decrease with increase in concrete age. This implies that the prolonged exposure of the concrete specimens to humid (swampy) environment has reduced the compressive strength of the concrete.

The equation of the regression line relating the average compressive strength and average Young modulus for concrete is given by:

$$
E(\sigma)=3695 e^{0.115 \sigma}
$$

with a correlation coefficient of $\mathrm{R}=0.987$. Where, $\mathrm{E}=$ Young modulus of elasticity and $\sigma=$ average compressive strength of concrete , and $\mathrm{e}=2.7183$. The Young modulus- compressive strength relationship is in contrast with Eurocode 2 "moistureunaffected" model which is:

$$
E_{c}=9500\left(\sqrt{f_{c}^{\prime}}+8\right) 0.33 \text {; where, }
$$

$\mathrm{E}_{\mathrm{c}}=$ static modulus of elasticity in MPa at 28 days and $\mathrm{f}_{\mathrm{c}}{ }^{\prime}=$ cylinder compressive strength in MPa at 28days

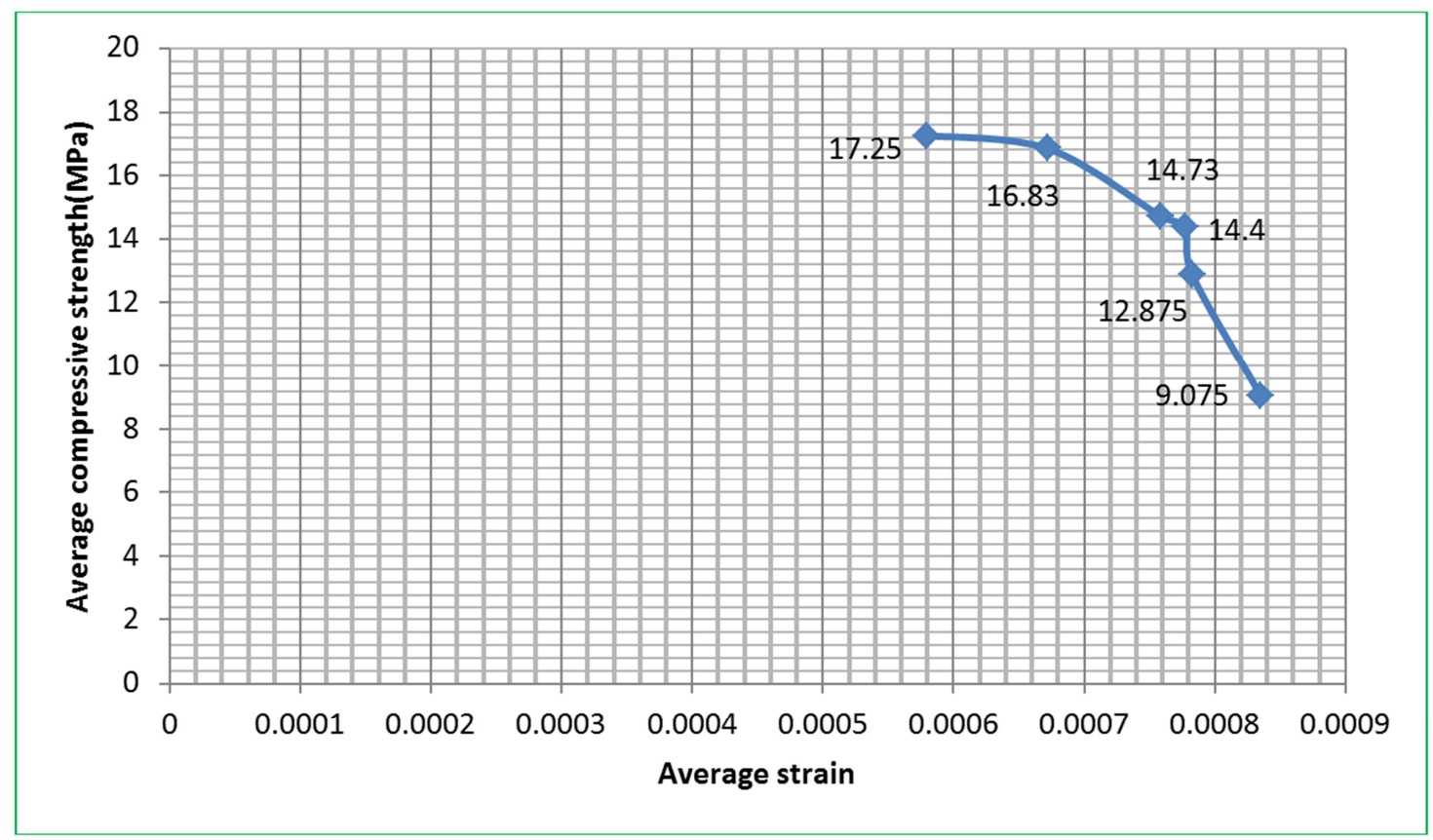

Figure 4. Relationship between the average strain and average Compressive strength of concrete.

From figure 4, table 2 and table 3, it can be observed that the average strain increases as the average compressive strength drops. The strain experiences a reduction with increment of cement dosage. Thus, the greater the cement content, the greater the resistance and dimensional stability of the specimens, with minimal triaxial -deformations. 


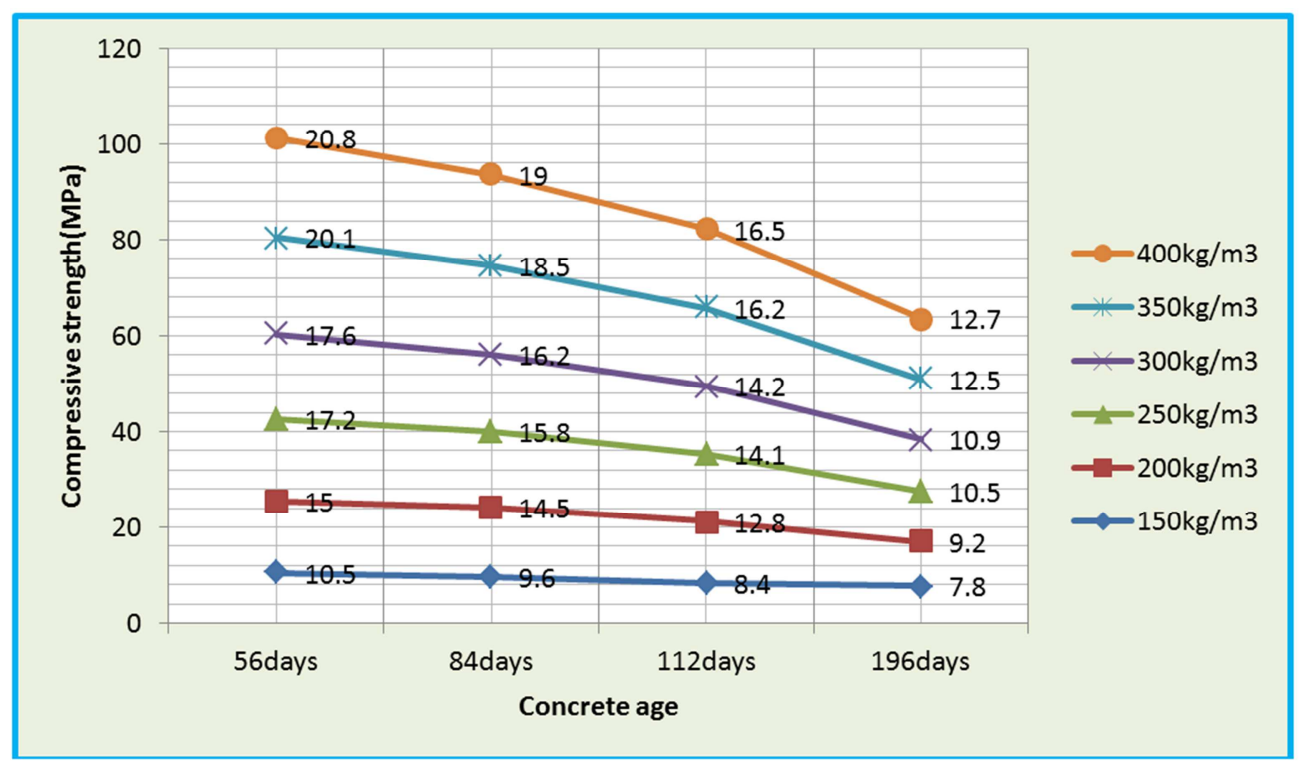

Figure 5. Relationship between the concrete age and Compressive strength of concrete.

From figure 5, it can be observed that the compressive strength of concrete subjected to the swampy environment reduces as the concrete age increases. This trend applies to concretes of all cement dosages. Notice that the compressive strength of concrete also goes up with increment in cement dosage. For concrete dosed at $150 \mathrm{Kg} / \mathrm{m}^{3}$, it can be observed that the compressive strengths are $10.5 \mathrm{MPa}, 9.6 \mathrm{MPa}, 8.4 \mathrm{MPa}$, and $7.8 \mathrm{MPa}$ for 56days, 84days, 112days, and 196days, respectively. Compressive strengths of $15 \mathrm{MPa}, 14.5 \mathrm{MPa}$, $12.8 \mathrm{MPa}$, and $9.2 \mathrm{MPa}$ were observed for 56days, 84days, 112days, and 196days, respectively for concrete dosed at $200 \mathrm{Kg} / \mathrm{m}^{3}$. For the duration of 56days, 84 days, 112 days, and 196days, the concrete witnessed compressive strengths of $17.2 \mathrm{MPa}, 15.8 \mathrm{MPa}, 14.1 \mathrm{MPa}$, and $10.5 \mathrm{MPa}$, respectively for concrete dosed at $250 \mathrm{Kg} / \mathrm{m}^{3}$. For concrete dosed at $300 \mathrm{Kg} / \mathrm{m}^{3}$, the compressive strengths are $17.6 \mathrm{MPa}$, 16.2MPa, $14.2 \mathrm{MPa}$, and 10.9MPa for 56days, 84days, 112days, and 196days, respectively. Compressive strengths of $20.1 \mathrm{MPa}, 18.5 \mathrm{MPa}, 16.2 \mathrm{MPa}$, and $12.5 \mathrm{MPa}$ were noticed for 56days, 84days, 112days, and 196days, respectively for concrete dosed at $350 \mathrm{Kg} / \mathrm{m}^{3}$. For concrete dosed at $400 \mathrm{Kg} /$ $\mathrm{m}^{3}$, compressive strengths of $20.8 \mathrm{MPa}, 19 \mathrm{MPa}, 16.5 \mathrm{MPa}$, and $12.7 \mathrm{MPa}$ were culled for 56days, 84 days, 112 days, and 196days, respectively.

Let us use the average strain value at highest cement dosage of $400 \mathrm{Kg} / \mathrm{m}^{3}$ to compute the critical stress using the interpolated Lagrange function. Considering tables 2 and 3, the average strain at highest cement dosage is 0.00058 .

Notice that this value is 6.03 times less than Eurocode 2 maximum deformation specification for concrete which is 0.0035. The strain is also 5.17 times less than the ACI code which specifies that a strain of 0.003 is maximum strain that concrete can reach, and the value used for design of concrete structural element. Thus, with respect to the codes above, the strain is within acceptable limits. It must be remarked that the most important factor in design is not to have exact design data but to have values within acceptable and safe engineering limits. Strain values are affected by the properties of the different ingredients of concrete, the exposure conditions of the concrete, the applied loading, etc.

From basic solid mechanics, the constitutive equation for Young modulus of elasticity,

$$
\mathrm{E}=\frac{\sigma}{\varepsilon}=\frac{17.25}{0.00058}=29741.38 \mathrm{MPa}
$$

Therefore, the average Young modulus of elasticity for the concrete specimens dosed at $400 \mathrm{Kg} / \mathrm{m}^{3}=29741.38 \mathrm{MPa}$. This value falls within the range of values of $\mathrm{E}$ published by the Department of Civil engineering, Sri Ramakrishna Institute of Technology.

Poisson's ratio

Poisson's ratio is a measure of the Poisson effect, the phenomenon in which a material tends to expand in directions perpendicular to the direction of compression [3, 12]. Conversely, if the material is stretched rather than compressed, it usually tends to contract in the directions transverse to the direction of stretching. It is a common observation when a rubber band is stretched, it becomes noticeably thinner. Again, the Poisson ratio will be the ratio of relative contraction to relative expansion and will have the same value as above.

Table 4. Computed triaxial strain values and average Poisson ratio of concrete.

\begin{tabular}{|c|c|c|c|c|c|c|}
\hline & \multicolumn{2}{|l|}{$150 \mathrm{Kg} / \mathrm{m}^{3}$} & \multicolumn{2}{|l|}{$200 \mathrm{Kg} / \mathrm{m}^{3}$} & \multicolumn{2}{|l|}{$250 \mathrm{Kg} / \mathrm{m}^{3}$} \\
\hline & $\varepsilon_{x}=\varepsilon_{z}$ & $\varepsilon_{y}$ & $\varepsilon_{x}=\varepsilon_{z}$ & $\varepsilon_{y}$ & $\varepsilon_{x}=\varepsilon_{z}$ & $\varepsilon_{y}$ \\
\hline AV. & 0.0002004 & 0.000835 & 0.0001565 & 0.0007825 & 0.00013995 & 0.0007775 \\
\hline$v=\frac{\varepsilon_{x}}{\varepsilon_{y}}$ & 0.24 & & 0.20 & & 0.18 & \\
\hline
\end{tabular}


Table 5. Computed triaxial strain values and average Poisson ratio of concrete.

\begin{tabular}{llllll}
\hline & $\mathbf{3 0 0} \mathbf{K g} / \mathbf{m}^{\mathbf{3}}$ & $\mathbf{3 5 0} \mathbf{K g} / \mathbf{m}^{\mathbf{3}}$ & \multicolumn{2}{c}{$\mathbf{4 0 0} \mathbf{K g} / \mathbf{m}^{\mathbf{3}}$} \\
\cline { 2 - 5 } & $\boldsymbol{\varepsilon}_{\boldsymbol{x}}=\boldsymbol{\varepsilon}_{\boldsymbol{z}}$ & $\boldsymbol{\varepsilon}_{\boldsymbol{y}}$ & $\boldsymbol{\varepsilon}_{\boldsymbol{x}}=\boldsymbol{\varepsilon}_{\boldsymbol{z}}$ & $\boldsymbol{\varepsilon}_{\boldsymbol{y}}$ & $\boldsymbol{\varepsilon}_{\boldsymbol{x}}=\boldsymbol{\varepsilon}_{\boldsymbol{z}}$ \\
\hline AV. & 0.000128945 & 0.0007585 & 0.00010095 & 0.000673 & 0.0000696 \\
$\nu=\frac{\varepsilon_{x}}{\varepsilon_{y}}$ & 0.17 & & 0.15 & & 0.00058 \\
\hline
\end{tabular}

From tables 4 and 5, it can be deduced that the greater the cement dosage, the lower the Poisson effect of concrete.

$$
\varepsilon_{x}=\text { lateral strain } ; \varepsilon_{y}=\text { axial strain }
$$

Poisson ratio is calculated as the ratio of the lateral strain to the axial strain. Strain is the ratio of either the elongation or shortening of the bricks to the original length.

Thus Poisson ratio $=\frac{\text { lateral strain }}{\text { axial strain }}$

$$
\varepsilon_{x} \text { or } \varepsilon_{y}=\frac{\text { extension or shortening }}{\text { original length }}
$$

The Poisson ratio shall be considered as the mean = $\frac{0.12+0.15+0.17+0.18+0.2+0.24}{6}$

$=0.177$. Therefore, the average Poisson ratio to be used for the finite element modelling

$=0.177$. Notice that this value falls below the average for a perfectly incompressible isotropic material deformed elastically at small strains which would have a Poisson's ratio of exactly 0.5 . The average Lame' constant for the concrete,

$$
\lambda=\frac{E v}{(1+v)(1-2 v)}=\frac{(29741.38)(0.177)}{(1+0.177)(1-2(0.177))}=6923.495 \mathrm{MPa}
$$

Figure 6 depicts a demoulded concrete specimen showing tri-axial directions

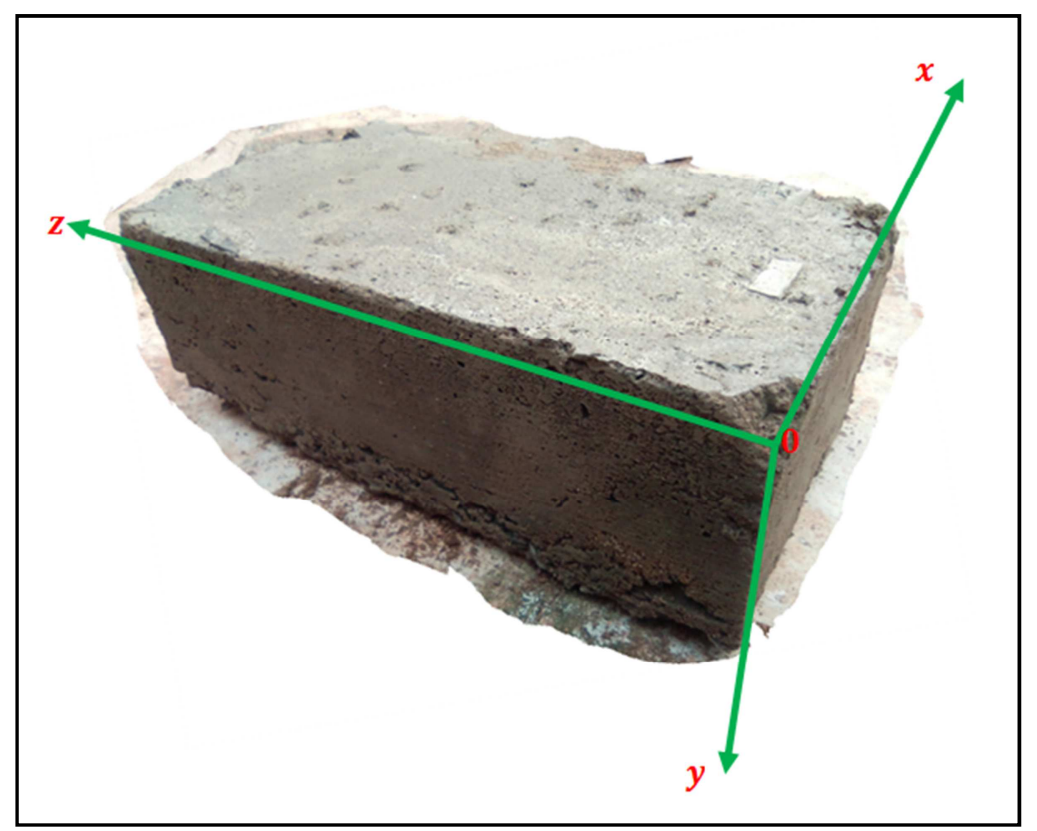

Figure 6. 3D-view of a demoulded concrete specimen showing tri-axial directions.

The bulk modulus $(\mathrm{K})$ of a substance is a measure of how resistant to compression that substance is. The representative bulk modulus for the concrete,

$$
\mathrm{K}=\frac{E}{3(1-2 v)}=\frac{29741.38}{3(1-2(0.177))}=15346.43 \mathrm{MPa}
$$

Since the representative $\mathrm{K}<E \Leftrightarrow 15346.43 \mathrm{MPa}<$ 29741.38MPa it implies that the concretes have an overall or combined poor compression performance with an elastic inefficiency when subjected to prolonged humidity.

\subsection{Modulus of Rigidity (Shear Modulus, G), Shear Stresses and Shear Angles}

The shear modulus is one of several quantities for measuring the stiffness of materials $[3,12]$.

$$
\mathrm{G}=\frac{\mathrm{E}}{2(1+v)}=\frac{29741.38}{2(1+0.177)}=12634.4 \mathrm{MPa}
$$

It can be observed that the representative shear modulus, $\mathrm{G}=12634.4 \mathrm{MPa}<E=29741.38 \mathrm{MPa}$. This discrepancy is indicative of the fact that the concrete has a greater overall elastic resistance to deformation than its resistance to shearing when subjected to prolonged humidity.

The shear stresses

For values of the shearing stress that do not exceed the proportional limit in shear, we can write for any homogeneous isotropic material, $\tau_{x y}=G \varepsilon_{y}$. Let us compute the shear stresses in the direction of compressive loading (ydirection). 
Table 6. Cement dosage and triaxial strain values, shear angle, and shear.

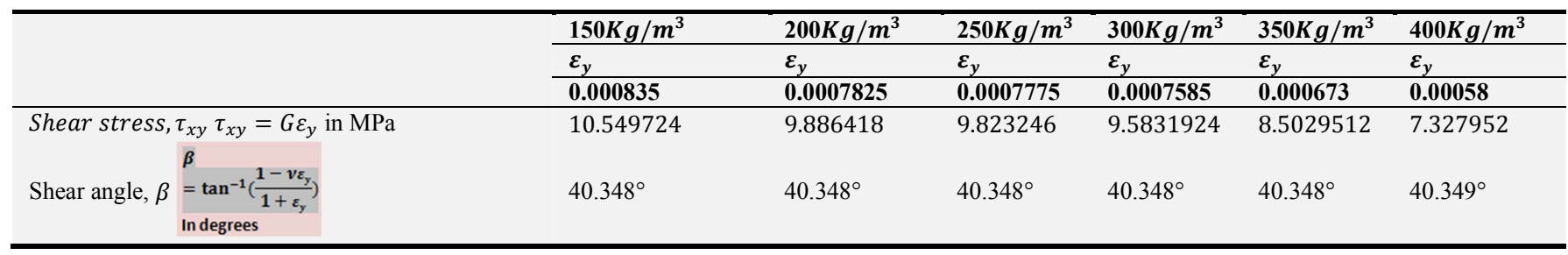

From table 6 , it can be seen that the shear stresses developed in the concrete specimens increase with reduced cement content. This explains why specimens with lower cement proportions easily fail. It can also be observed that the angle of shear is closer to $45^{\circ}$ which is commonly regarded as an approximate shear angle of brick masonry.

\subsection{Advanced Failure Analysis of the Concrete}

The failure analysis is performed by using the Principal stress theory and Von Mises stress failure criterion initially proposed by the Polish engineer, Tytus Maksymilian Huber in 1904 and further developed by the Austrian engineer, Richard Edler von Mises in 1913.

Let us compute the principal stresses of the concrete specimens considering the least dosage of $150 \mathrm{~kg} / \mathrm{m}^{3}$ and maximum dosage of $400 \mathrm{~kg} / \mathrm{m}^{3}$ in order to gauge the relative numerical balance of von Mises stress (that is whether von Mises stress is increasing with dosage or not). From tables 2 and 3 , the average compressive strengths for concrete at cement dosages of $150 \mathrm{~kg} / \mathrm{m}^{3}$ and $400 \mathrm{~kg} / \mathrm{m}^{3}$ at ambient temperature are 9.075 $\mathrm{MPa}$ and $17.25 \mathrm{MPa}$, respectively.
From tables 2 and 3, the average elastic modulus and Poisson ratio for concrete dosed at $150 \mathrm{~kg} /$ $\mathrm{m}^{3}$ are $10868.26 \mathrm{MPa}$ and 0.24 , respectively. For concrete dosed at $400 \mathrm{~kg} / \mathrm{m}^{3}$, the average elastic modulus and Poisson ratio are $29741.38 \mathrm{MPa}$ and 0.12 , respectively.

$\Rightarrow$

For concrete dosed at $150 \mathrm{~kg} /$

$\mathrm{m}^{3}$, the shear modulus, $\mathrm{G}=\frac{\mathrm{E}}{2(1+v)}=\frac{10868.26}{2(1+0.24)}=4382.363 \mathrm{MPa}$

The shear stress for concrete dosed at $150 \mathrm{~kg} / \mathrm{m}^{3}$, $\tau_{\mathrm{xy}}=\mathrm{G} \varepsilon_{\mathrm{y}}=4382.363(0.000835)=3.659 \mathrm{MPa} \Rightarrow$ For concrete dosed at $400 \mathrm{~kg} / \mathrm{m}^{3}$, the shear modulus,

$$
\mathrm{G}=\frac{\mathrm{E}}{2(1+v)}=\frac{29741.38}{2(1+0.12)}=13277.402 \mathrm{MPa}
$$

The shear stress for concrete dosed at $400 \mathrm{~kg} / \mathrm{m}^{3}$,

$$
\tau_{x y}=G \varepsilon_{y}=13277.402(0.00058)=7.701 \mathrm{MPa}
$$

Considering the concrete specimens to be perfectly orthotropic, the principal stresses are computed as follows:

For concrete dosed at $150 \frac{\mathrm{kg}^{3}}{\mathrm{~m}}$,

$$
\sigma_{1}=\frac{\left(\sigma_{x}+\sigma_{y}\right)}{2}+\sqrt{\left(\frac{\sigma_{x}+\sigma_{y}}{2}\right)^{2}+\tau_{x y}^{2}}=\frac{(9.075+9.075)}{2}+\sqrt{\left(\frac{9.075+9.075}{2}\right)^{2}+(7.2352)^{2}}=20.681 \Rightarrow \sigma_{1}=20.681 \mathrm{MPa}
$$

For concrete dosed at $150 \frac{\mathrm{kg}^{3}}{\mathrm{~m}}$,

$$
\sigma_{2}=\frac{\left(\sigma_{x}+\sigma_{y)}\right.}{2}-\sqrt{\left(\frac{\sigma_{x}+\sigma_{y}}{2}\right)^{2}+\tau_{x y}^{2}}=\frac{(9.075+9.075)}{2}-\sqrt{\left(\frac{9.075+9.075}{2}\right)^{2}+(7.2352)^{2}}=-2.531 \Rightarrow \sigma_{2}=-2.531 \mathrm{MPa}
$$

From the results of principal stresses we can compare with the values on tables 2 and 3 to see test specimens that would fail to satisfy the engineering service life of the concrete.

According to the Tresca's Yield Criterion, $\left|\sigma_{1}\right| \geq \sigma_{\text {yield }}$;

$$
\sigma_{V M}=\sqrt{\sigma_{x x}^{2}+\sigma_{y y}^{2}+\sigma_{z z}^{2}-\sigma_{x x} \sigma_{y y}-\sigma_{y y} \sigma_{z z}-\sigma_{z z} \sigma_{x x}+3\left(\tau_{x y}^{2}+\tau_{y z}^{2}+\tau_{z x}^{2}\right)}
$$

Since concrete orthotropicity, $\sigma_{x} \equiv \sigma_{y} \equiv \sigma_{z}$

For concrete dosed at $150 \mathrm{~kg} / \mathrm{m}^{3}, \tau_{z x}=\tau_{y z}=\frac{G \sigma}{E}=\frac{4382.363 \times 9.075}{10868.26}=3.659 \mathrm{MPa}$

Let us first evaluate the expression in the radicand,

$$
\begin{gathered}
9.075^{2}+9.075^{2}+9.075^{2}-(9.075)(9.075)-(9.075)(9.075)-(9.075)(9.075)+3\left(7.2352^{2}+2\left(3.659^{2}\right)\right)= \\
237.374 \Rightarrow \text { Von Mises stress for concrete dosed at } 150 \mathrm{~kg} / \mathrm{m}^{3}, \sigma_{V M}=\sqrt{237.374}=15.407 \mathrm{MPa}
\end{gathered}
$$

Further assessment of concrete dosed at $150 \mathrm{~kg} / \mathrm{m}^{3}$ indicates the following: 
1) Maximum distortion energy $=\frac{(1+v) \sigma^{2} V M}{3 E}=\frac{(1+0.24)(15.407)^{2}}{3(10868.26)}=0.009028 \mathrm{MJ} / \mathrm{m}^{3}=9.028 \mathrm{KJ} / \mathrm{m}^{3}$

For concrete dosed at $400 \frac{\mathrm{kg}^{3}}{\mathrm{~m}}$,

$$
\sigma_{1}=\frac{\left(\sigma_{x}+\sigma_{y)}\right.}{2}+\sqrt{\left(\frac{\sigma_{x}+\sigma_{y}}{2}\right)^{2}+\tau^{2} x y}=\frac{(17.25+17.25)}{2}+\sqrt{\left(\frac{17.25+17.25}{2}\right)^{2}+(5.0256)^{2}}=35.217 \Rightarrow \sigma_{1}=35.217 \mathrm{MPa}
$$

For concrete dosed at $400 \mathrm{~kg} / \mathrm{m}^{3}$,

$$
\sigma_{2}=\frac{\left(\sigma_{x}+\sigma_{y}\right)}{2}-\sqrt{\left(\frac{\sigma_{x}+\sigma_{y}}{2}\right)^{2}+\tau_{x y}^{2}}=\frac{(17.25+17.25)}{2}-\sqrt{\left(\frac{17.25+17.25}{2}\right)^{2}+(5.0256)^{2}}=35.217 \Rightarrow \sigma_{2}=-0.7172 \mathrm{MPa}
$$

From the results of principal stresses we can compare with the values on tables 2 and 3 to see test specimens that would fail to satisfy the engineering service life of the concrete. According to the Tresca's Yield Criterion, $\left|\sigma_{1}\right| \geq \sigma_{\text {yield }}$; which is satisfied.

For concrete dosed at $400 \mathrm{~kg} / \mathrm{m}_{3}$,

$$
\tau_{z x}=\tau_{y z}=\frac{G \sigma}{E}=\frac{12634.4 \times 17.25}{29741.38}=7.328 \mathrm{MPa}
$$

But the expression

$17.25^{2}+17.25^{2}+17.25^{2}-(17.25)(17.25)-(17.25)(17.25)-(17.25)(17.25)+3\left(7.328^{2}+2\left(7.328^{2}\right)\right)=483.296$

$\Rightarrow$ Von Mises stress for concrete dosed at $400 \mathrm{~kg} / \mathrm{m}^{3}, \sigma_{V M}=\sqrt{483.296}=21.984 \mathrm{MPa}$

Further assessment of concrete dosed at $400 \mathrm{~kg} / \mathrm{m}^{3}$ indicates the following:

2) Maximum distortion energy $=\frac{(1+v) \sigma^{2} V M}{3 E}=\frac{(1+0.12)(21.984)^{2}}{3(29741.38)}=0.006067 \mathrm{MJ} / \mathrm{m}^{3}=6.067 \mathrm{KJ} / \mathrm{m}^{3}$

\section{Conclusion}

The average compressive strength of concrete increases with increase in average Young modulus as the cement dosage goes up. Thus, the greater the cement content, the greater the compressive strength of the samples. However, the compressive strengths witnessed a decrease with increase in concrete age. This implies that the prolonged exposure of the concrete specimens to humid (swampy) environment has reduced the compressive strength of the concrete.

It was observed that the compressive strength of concrete subjected to the swampy environment reduces as the concrete age increases. This trend applies to concretes of all cement dosages. Notice that the compressive strength of concrete also goes up with increment in cement dosage. For concrete dosed at $150 \mathrm{Kg} / \mathrm{m}^{3}$, it can be observed that the compressive strengths are $10.5 \mathrm{MPa}, 9.6 \mathrm{MPa}, 8.4 \mathrm{MPa}$, and $7.8 \mathrm{MPa}$ for 56days, 84days, 112days, and 196days, respectively. Compressive strengths of $15 \mathrm{MPa}, 14.5 \mathrm{MPa}, 12.8 \mathrm{MPa}$, and 9.2MPa were observed for 56days, 84days, 112days, and 196days, respectively for concrete dosed at $200 \mathrm{Kg} / \mathrm{m}^{3}$. For the duration of 56days, 84days, 112days, and 196days, the concrete witnessed compressive strengths of $17.2 \mathrm{MPa}$, $15.8 \mathrm{MPa}, 14.1 \mathrm{MPa}$, and $10.5 \mathrm{MPa}$, respectively for concrete dosed at $250 \mathrm{Kg} / \mathrm{m}^{3}$. For concrete dosed at $300 \mathrm{Kg} / \mathrm{m}^{3}$, the compressive strengths are $17.6 \mathrm{MPa}, 16.2 \mathrm{MPa}, 14.2 \mathrm{MPa}$, and $10.9 \mathrm{MPa}$ for 56days, 84days, 112days, and 196days, respectively. Compressive strengths of $20.1 \mathrm{MPa}, 18.5 \mathrm{MPa}$, $16.2 \mathrm{MPa}$, and $12.5 \mathrm{MPa}$ were noticed for 56days, 84 days, 112days, and 196days, respectively for concrete dosed at
$350 \mathrm{Kg} / \mathrm{m}^{3}$. For concrete dosed at $400 \mathrm{Kg} / \mathrm{m}^{3}$, compressive strengths of $20.8 \mathrm{MPa}, 19 \mathrm{MPa}, 16.5 \mathrm{MPa}$, and $12.7 \mathrm{MPa}$ were culled for 56days, 84days, 112days, and 196days, respectively.

Concrete dosed at $150 \mathrm{~kg} / \mathrm{m}^{3}$ recorded a Von Mises stress of $15.407 \mathrm{MPa}$, while concrete dosed at $400 \mathrm{~kg} / \mathrm{m}^{3}$ recorded a higher von Mises stress of $21.984 \mathrm{MPa}$. The Von Mises stresses are far greater than most of the average uni-axial failure stresses displayed on tables 2 and 3. This is a clear indication of the high overall degree of brittle failure due to deviatoric stresses at point of yielding for the concrete brands. The maximum distortion energy for concrete dosed at $150 \mathrm{~kg} /$ $m^{3}$ is $9.028 \mathrm{KJ} / \mathrm{m}^{3}$, while that dosed at $400 \mathrm{~kg} / \mathrm{m}^{3}$ has a distortion energy of $6.067 \mathrm{KJ} / \mathrm{m}^{3}$. Therefore, the greater the cement dosage, the lesser the propensity of the concretes failing with great dimensional instability (shape change).

The representative bulk modulus for concrete dosed at $400 \mathrm{~kg} / \mathrm{m}^{3}, \mathrm{~K}<E \Leftrightarrow 15346.43 \mathrm{MPa}<29741.38 \mathrm{MPa}$, impying that the concretes have an overall or combined poor compression performance with an elastic inefficiency when subjected to prolonged humidity. The representative shear modulus, $\mathrm{G}=12634.4 \mathrm{MPa}<E=29741.38 \mathrm{MPa}$. This discrepancy is indicative of the fact that the concrete has a greater overall elastic resistance to deformation than its resistance to shearing when subjected to prolonged humidity. The representative modulus of elasticity for the concrete dosed at $400 \mathrm{~kg} / \mathrm{m}^{3}$ is $29741.38 \mathrm{MPa}$, the Poisson ratio is 0.177 , and the average density of specimens is $2374.017 \mathrm{~kg} / \mathrm{m}^{3}$.

\section{Conflicts of Interest}

The authors declare that there are no conflicts of interest 
regarding the publication of this article.

\section{Acknowledgements}

We thank the technicians of the Material and Geotechnical Laboratories of Bambuiy Engineering, Bamenda, Cameroon.

\section{References}

[1] Ajith (2017), Concrete and Highway Materials Laboratory 10cvl78, Channabasaveshwara Institute of Technology (an Iso 9001: 2015 Certified institution) AIP conference proceedings 2128, 020011 (2019); https://doi.org/10.1063/1.51179232128, 020011@ 2019 author (s).

[2] Arum and Olotuah (2006), Making of strong and durable concrete, Emirates journal for engineering research, 11 (1), 25-31 (2006).

[3] Autar (2006), Mechanics of composite materials, Taylor and Francis Group, Second edition.

[4] Beall, C. (2000). Water penetration in building envelopes. Retrieved from http://www.rci-online.org/interface/2000-10beall.pdf.

[5] Briffett, C. (1994). Building Maintenance Technology in Tropical Climates-Investigating dampness problem in buildings, Singapore. Singapore University Press.

[6] British Standards, BS 882 (1992), Specification for Aggregates from Natural Sources for Concrete. British Standard Institution.

[7] British Standards, BS 1881 (1970), Methods of Testing Concrete, Part 2, British Standard Institution.

[8] Burkinshaw, R., \& Parrett, M. (2004). Diagnosing damp. Coventry: RICS BOOK.
[9] Cukierski, (1999). Moisture condensation at the windows. Housing Fact Sheets. Cornell Cooperative Extension.

[10] Halim, A. A., \& Halim, A. Z. (2010). An analysis of Dampness Study on Heritage Buildings: A Case Study Ipoh Old Post Office Building and Suluh Budiman Building, UPSI, Perak, Malaysia. Journal of Sustainable Development, 3 (4), 171-182.

[11] Halim, A. A., Harun, S. N., \& Hamid, Y. (2012). Diagnosis of dampness in conservation of historic buildings. Journal Design Built.

[12] Horia et al (2015), Mechanical properties of hardened high strength concrete, 9th international conference interdisciplinarity in engineering, inter-eng 2015, 8-9 october 2015, tirgu-mures, Romania.

[13] Jeetendra and Sudip (2019), Effect of coarse aggregate sources on the compressive strength of various grade of nominal mixed concrete, department of civil engineering, khwopa engineering college, libali-08, bhaktapur, Nepal miroslava (2015), composite materials, Vsb -technical university of ostrava.

[14] Osuji and Ukeme (2015), Effects of elevated temperature on compressive strength of concrete: a case study of grade 40 concrete, Nigerian journal of technology (Nijotech) vol. 34 no. 3, July 2015, pp. 472-477.

[15] Pedro and David (2003), the effects of aggregates characteristics on the performance of Portland cement concrete, international center for aggregates research aggregates foundation for technology, research, and education.

[16] Soty and Hiroshi (2013), Relationship between splitting tensile strength and compressive strength of concrete at early age with different types of cement sand curing temperature histories. 